\title{
A Low Velocity Zone along the Chaochou Fault in Southern Taiwan: Seismic Image Revealed by a Linear Seismic Array
}

\author{
Hsin-Chieh $\mathrm{Pu}^{1}$, Cheng-Horng Lin ${ }^{2,}{ }^{*}$, Kuo-Liang Wen ${ }^{1}$, Tao-Ming Chang ${ }^{3}$, \\ Yih-Hsiung Yeh ${ }^{2}$, and Wen-Yen Chang ${ }^{4}$ \\ ${ }^{1}$ Institute of Geophysics, National Central University, Jhongli, Taiwan \\ ${ }^{2}$ Institute of Earth Sciences, Academia Sinica, Taipei, Taiwan \\ ${ }^{3}$ National Center for Research on Earthquake Engineering, Taipei, Taiwan \\ ${ }^{4}$ National Science Council, Taipei, Taiwan
}

Received 11 August 2009, accepted 6 November 2009

\begin{abstract}
The Chaochou fault is one of the major boundary faults in southern Taiwan where strong convergence has taken place between the Eurasian and Philippine Sea plates. The surface fault trace between the Pingtung plain and the Central Range follows a nearly N-S direction and stretches to $80 \mathrm{~km}$ in length. In order to examine the subsurface structures along the Chaochou fault, a linear seismic array with 14 short-period stations was deployed across the fault to record seismic data between August and December 2001. Detailed examination of seismic data generated by 10 local earthquakes and recorded by the linear array has shown that the incidence angles of the first P-waves recorded by several seismic stations at the fault zone were significantly larger than those located farther away from the fault zone. This difference might reflect the lateral variation of velocity structures across the Chaochou fault. Further examination of ray-paths of seismic wave propagation indicates that a low-velocity zone along the Chaochou fault is needed to explain the significant change in incidence angles across the fault zone. Although we do not have adequate information to calculate the exact geometry of the fault zone well, the variation in incidence angles across the fault can be explained by the existence of a low-velocity zone that is about $3 \mathrm{~km}$ in width on the surface and extends downward to a depth of $5 \mathrm{~km}$. The low-velocity zone along the Chaochou fault might imply that the fault system consists of several splay faults on the hanging wall in the Central Range.
\end{abstract}

Key words: Chaochou fault, Linear seismic array, Fault zone, Incidence angles

Citation: Pu, H. C., C. H. Lin, K. L. Wen, T. M. Chang, Y. H. Yeh, and W. Y. Chang, 2010: A low velocity zone along the Chaochou fault in southern Taiwan: Seismic image revealed by a linear seismic array. Terr. Atmos. Ocean. Sci., 21, 781-790, doi: 10.3319/TAO.2009.11.06.01(T)

\section{INTRODUCTION}

Fault zone structures play an important role in understanding faulting processes in the past as well as future potential earthquake behavior and impending seismic hazards near active faults. One of the most interesting fault zone structures is the low velocity zone (LVZ) within the major boundary fault. For example, a narrow LVZ running from the surface down to the seismogenic depths was clearly found beneath the San Andreas fault in North America (Li et al. 1994) and the Nojima fault in Japan (Ito et al. 1996). The LVZ within those faults might be considered a fracture zone resulting from the repeated faulting processes along the ma-

\footnotetext{
* Corresponding author

E-mail:lin@earth.sinica.edu.tw
}

jor fault and/or several nearby splay faults in the past. As a result, the LVZ within the fault zone might be significantly associated with the major seismogenic zone responsible for generating large potential earthquakes in the future.

Although the importance of knowing the structural details of a fault zone is well recognized, imaging fault zone structure remains a challenge for scientists. Aside from using traditional geological surveys on the surface or drilling at shallow depths (i.e., Boness and Zoback 2004; Chéry and Zoback 2004; Morrow et al. 2007), scientists have largely found deep fault zone structures with low velocity characteristics by studying the seismic waves trapped within the LVZ ( $\mathrm{Li}$ et al. 1990, 1994; Ito and Kuwahara 1996; Kuwahara et al. 2001). 
In this study, we deployed a dense linear seismic array across the Chaochou fault in southern Taiwan to study the fault zone structure. It was interesting to note that the particle motions of the first P-waves generated by 10 local earthquakes and recorded at the seismic array showed that the incidence angles changed significantly across the fault zone. This feature provided useful information to investigate the possibility of an LVZ beneath the Chaochou fault. Major fault zone structures can be further estimated by modeling ray-path characteristics propagated across the fault zone.

\section{GEOLOGICAL BACKGROUND}

The Chaochou fault is one of the major boundary faults in the southern Taiwan region between the Central Range and the Western Plain (Ho 1988). The fault trace on the surface has been marked by the Central Geological Survey (Lin et al. 2000) according to both topographic features and the lithologic boundary along a clear line, which is about $80 \mathrm{~km}$ in length and strikes in a nearly N-S direction (Fig. 1). This fault separates the Pingtung Plain (Western Coastal Plain) from the Central Range (Ho 1988). Strong crustal exhumation has also taken place in the Central Range starting a few of million years ago (Lin 2002). The northern extension of this fault might be linked to either the Chuchih fault that divides the Western Foothills and the Hsueshan Range, or the Lishan fault, which is the major geological boundary between the Hsueshan Range and the eastern Backbone Ridge (Ho 1988).

Like most of the active faults in western Taiwan, the Chaochou fault is often considered a reverse fault caused by the strong convergence between the Eurasian and Philippine Sea plates. The dipping angle of the fault is about $70-80^{\circ}$ toward the east (Hsieh 1970; Chiang 1971; Hsu and Chang 1979). Several geological profiles across the Chaochou fault were constructed by Hasseler (2004) according to the seismic section from Chiang (1971). Based on recent GPS observations, the N-S trending of the Chaochou fault was further interpreted to be nearly pure reverse faulting (Wiltschko et al. 2002; Ching et al. 2007). Although there is no significant seismicity along the Chaochou fault, it was first considered to be an active fault based on photogeological analyses (Howard 1962; Bonilla 1975, 1977, 1999). Furthermore, crustal deformation observed in the GPS survey shows vertical velocities that gradually increase across the Chaocahou fault (Ching et al. 2007). Thus, all tectonic characteristics, geological surveys and GPS observations in addition to the great differences in stress and strain fields at both sides of the Chaochou fault (Chang et al. 2003) lead to the conclusion that the Chaochou fault might be one of the major suspected active faults in Taiwan (Lin et al. 2000).

\section{SEISMIC ARRAY AND DATA}

To investigate the fault zone structures across the Chaochou fault, we examined earthquake data recorded by a densely linear seismic array with 14 seismometers (Fig. 1). The linear array was deployed across the Chaochou fault between August and December 2001. The total coverage of these 14 seismic stations was about $25 \mathrm{~km}$ in length. Six stations (W01 - W06) were deployed in the Pingtung plain with an average station spacing of $2-3 \mathrm{~km}$, while other eight stations (W07 - W14) were deployed in the Central Range and had a smaller spacing of $1-2 \mathrm{~km}$. The surface trace of the Chaochou fault, according to the map of active faults in Taiwan published by the Central Geological Survey (a)

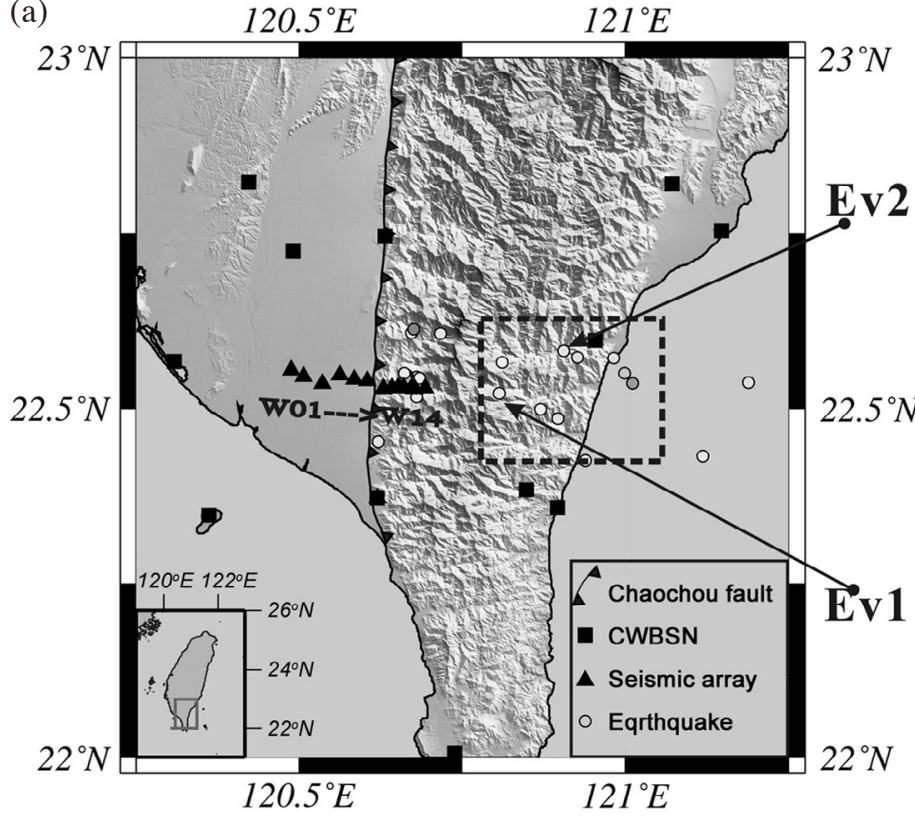

(b)

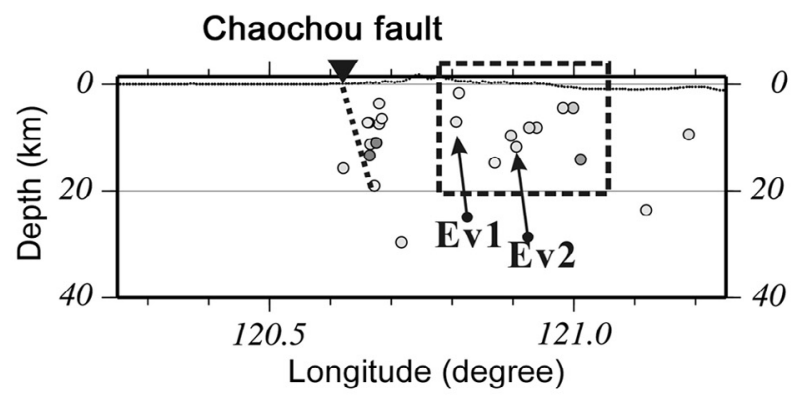

Fig. 1. (a) Locations of a linear seismic array with 14 shortperiod stations (triangles) and epicenters of some earthquakes (circles) reported by CWB within the dotted frame during 2001/08 - 12. The surface trace of Chaochou fault (line with triangles) is plotted on the topographic relief. (b) Depth projection of the earthquakes on the west-east profile across the Chaochou fault (inverted triangle), dipping eastward (dashed line). The events within the dashed square were analyzed in this study. For these events, Ev1 and Ev2 would be traced the ray-path at each station below. 
(Lin et al. 2000), is located near station W07. Each of the stations was equipped with a three-component short-period sensor (Lennartz LE-3Dlite) with a dominant frequency of $1 \mathrm{~Hz}$, and all seismic data were continuously recorded using a high-resolution digital data logger (Samtac-801H, Tokyo Sokusin) with a sample rate of $100 \mathrm{~Hz}$.

To extract useful seismic data recorded at the dense linear array, we examined the earthquake catalog published by the Central Weather Bureau for the events that occurred at the study area. During the five-month observation period, few earthquakes occurred beneath the eastern side of the linear array of the Central Range and no events were observed on the other side beneath the Pingtung Plain (Fig. 1). The locations of the earthquakes that did happen were well identified by the seismic data recorded by the regional seismic network, the Central Weather Bureau Seismic Network (CWBSN) (Shin et al. 2000). The projection of local earthquakes on the west-east profile shows that some earthquakes were clustered beneath the Chaochou fault (Fig. 1b). However, the seismic zone with a west-dipping trend was not consistent with the dip angle of the fault (Hsieh 1970; Chiang 1971; Hsu and Chiang 1979).

\section{DATA ANALYSES}

The particle motions of the first $\mathrm{P}$-waves generated by some local earthquakes (Table 1) on the eastern side of the fault showed some significant seismic characteristics to reveal fault zone structures within the Chaochou fault. The incidence angles of seismic waves can be obtained from the polarizations of the first $\mathrm{P}$-waves generated by all 10 of the local earthquakes that occurred in the eastern side of the linear seismic array (Fig. 1). A generally strong lineation of particle motions of the first $\mathrm{P}$-wave recorded at Station W04 shows the incidence angle of impulsive arrivals is clear and reliable (Fig. 2). Although particle motions of the first P-waves at some stations have elliptical (anisotropic) features, most of them were dominated by a clear lineation. It is interesting to note that the incidence angles recorded at seismic stations within and nearby the fault zone (W06 W08) were significantly larger than those recorded at other stations (W01 - W05 and W09 - W15) at both sides of the Chaochou fault (Fig. 3). The incidence angles recorded at the fault zone were about $25-40^{\circ}$. For example, the incidence angles were $\sim 40^{\circ}$ at Station W08, 33 ${ }^{\circ}$ at Station W07 and $\sim 25^{\circ}$ at Station W06. On the other hand, the incidence angles recorded on both sides of the fault (Stations W03 - W05 at the footwall and W09 - W13 at the hanging wall) all measured less than $20^{\circ}$.

An extremely similar pattern in incidence angle measurements was identified using the seismic data generated by another earthquake (Fig. 4). The incidence angles recorded at the fault zone ranged from $20-33^{\circ}$. For example, the incidence angles were $\sim 25^{\circ}$ at Station W08, $\sim 33^{\circ}$ at Station W07 and $20^{\circ}$ at Station W06. But, all of the incidence angles recorded at both sides of the fault (Stations W03 and W05 at the footwall and stations W09 - W13 at the hanging wall) were less than $20^{\circ}$. Although some uncertainties might exist due to elliptical motions at some stations, the differences between incidence angles of the fault zone and

Table 1. Earthquake parameters shown within the dashed square of Fig. 1.

\begin{tabular}{cccccc}
\hline Event ID & Time $(\mathbf{y y} / \mathbf{m m} / \mathbf{d d} / \mathbf{h h}: \mathbf{m i n})$ & Longitude $\left({ }^{\circ} \mathbf{E}\right)$ & Latitude $\left({ }^{\circ} \mathbf{N}\right)$ & Depth $(\mathbf{k m})$ & Magnitude $\left(\mathbf{M}_{\mathbf{L}}\right)$ \\
\hline Ev1 & $01 / 08 / 08 / 03: 27$ & 120.807 & 22.521 & 7.05 & 2.29 \\
Ev2 & $01 / 11 / 12 / 08: 49$ & 120.905 & 22.582 & 11.72 & 2.28 \\
Ev3 & $01 / 08 / 25 / 21: 23$ & 120.999 & 22.550 & 4.43 & 3.03 \\
Ev4 & $01 / 10 / 03 / 20: 33$ & 120.897 & 22.485 & 9.63 & 2.33 \\
Ev5 & $01 / 10 / 10 / 03: 56$ & 121.189 & 22.537 & 9.40 & 2.42 \\
Ev6 & $01 / 10 / 23 / 06: 48$ & 120.870 & 22.499 & 14.75 & 1.99 \\
Ev7 & $01 / 11 / 18 / 01: 26$ & 120.982 & 22.572 & 4.45 & 2.46 \\
Ev8 & $01 / 11 / 20 / 10: 05$ & 120.939 & 22.425 & 8.11 & 2.41 \\
Ev9 & $01 / 11 / 21 / 05: 24$ & 120.927 & 22.573 & 8.14 & 2.61 \\
Ev10 & $01 / 11 / 21 / 07: 51$ & 121.011 & 22.536 & 14.03 & 3.48 \\
\hline
\end{tabular}


(a)

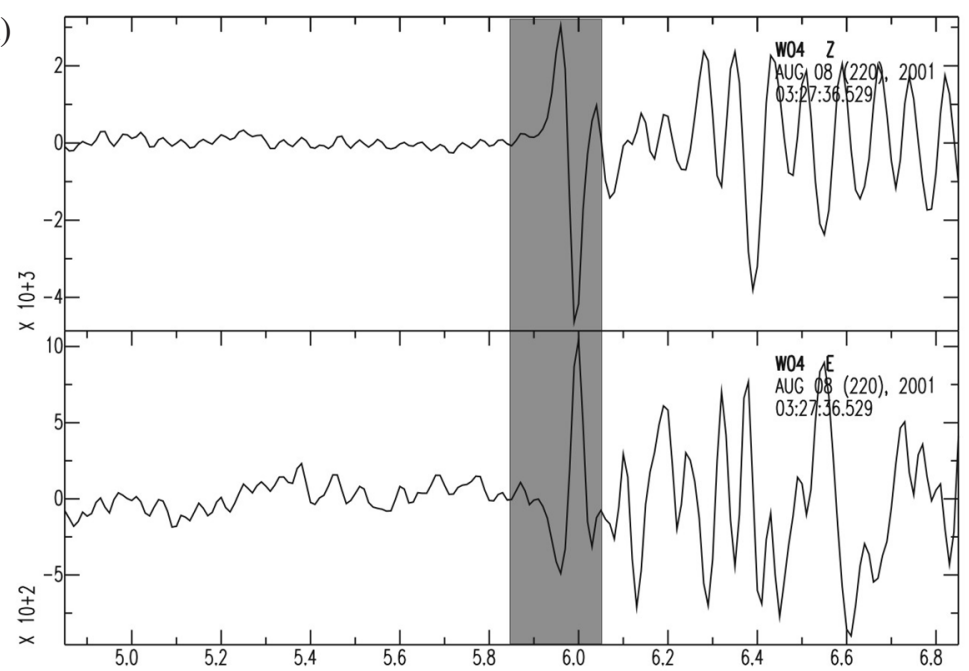

(b)

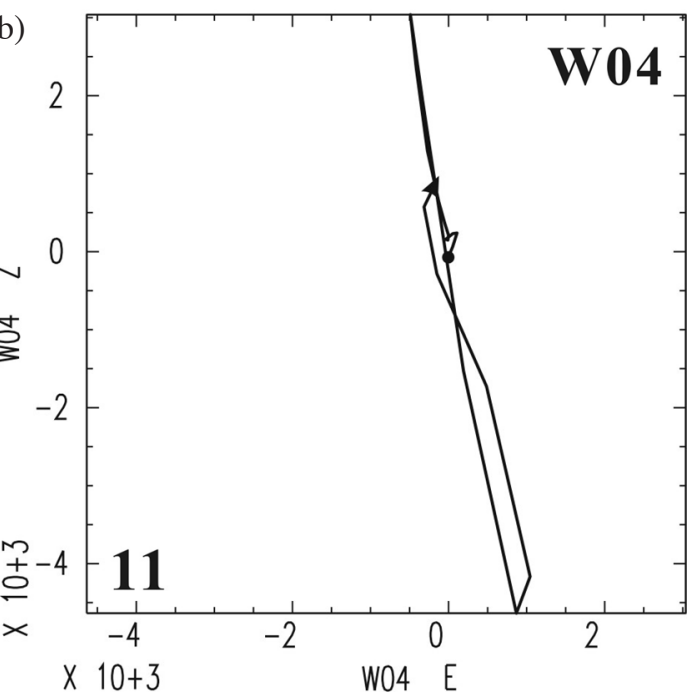

Fig. 2. An example of seismograms in the vertical and horizontal (W-E) components of the first P-wave arrivals recorded at Station W04 (a) and a linear polarization of the first-motions within 0.2 seconds (b). The number in right panel indicates the incident angle of polarization.

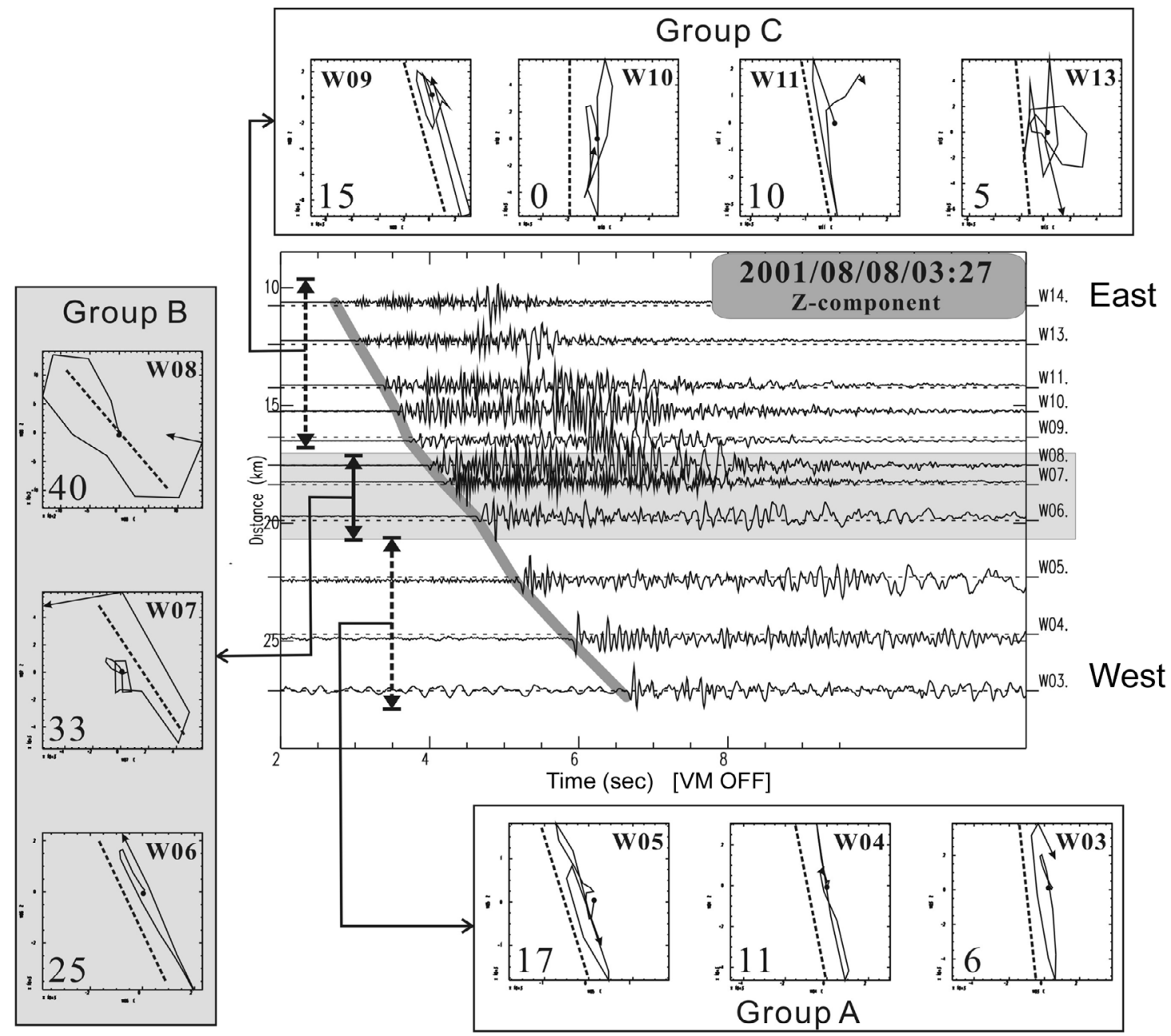

Fig. 3. Seismograms (middle panel) and their linear polarizations (small boxes) of the first P-waves generated by Ev1 and recorded at seismic arrays across the Chaochou fault. The seismograms have been separated into three groups recorded at stations in the footwall (Group A: W03 - W05), fault zone (Group B: W06 - W08) and hanging wall (Group C: W09 - W14). The number in bottom left corner of each box indicates the incident angle of polarization. 

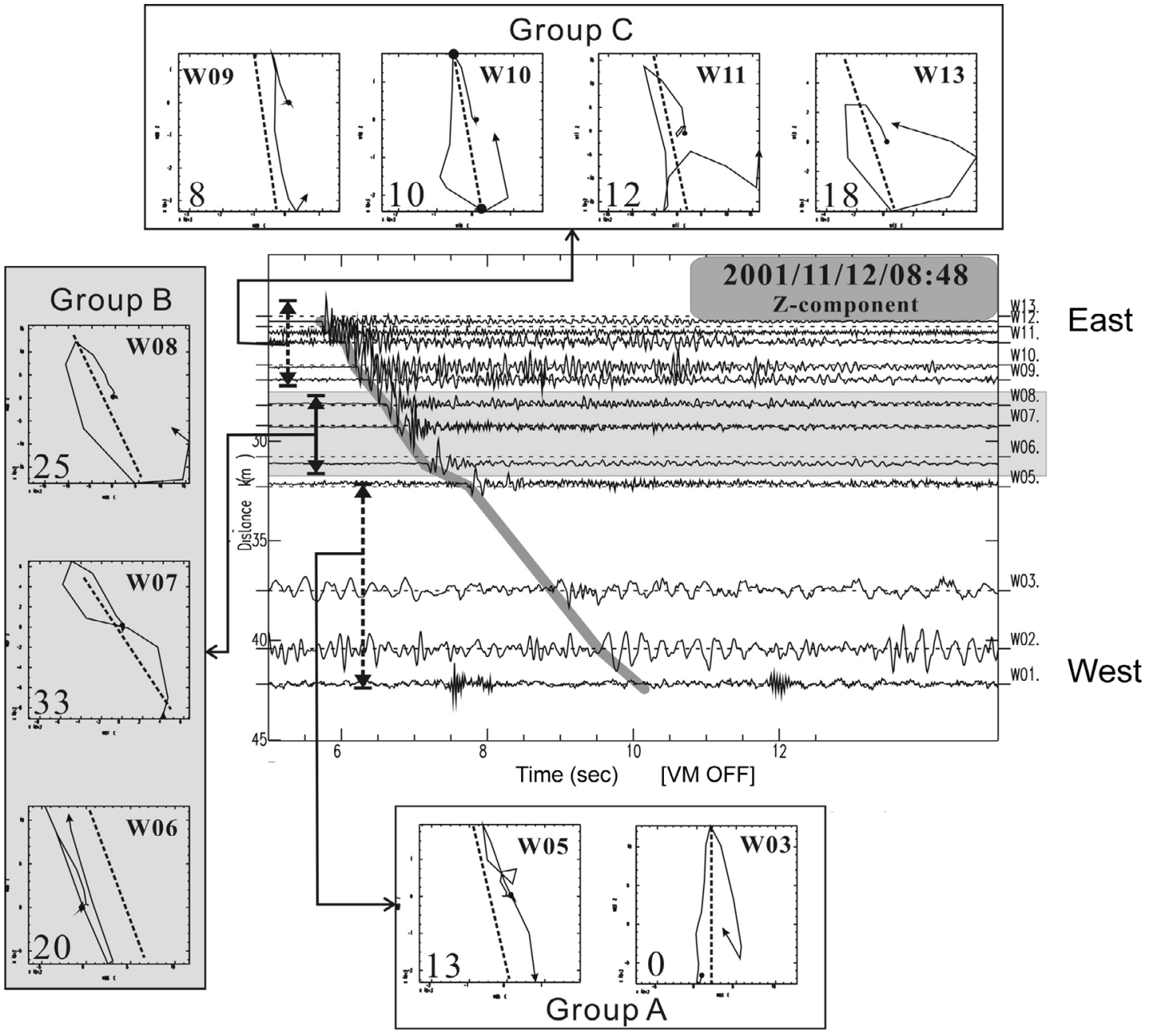

Fig. 4. Seismograms and their linear polarizations of the first P-waves generated by Ev2 and recorded at seismic arrays across the Chaochou fault. As shown in Fig. 3, the seismograms have been separated into three groups.

away from the fault were significant (Fig. 5). In fact, these differences were not only detected from the two local earthquakes in Figs. 3 and 4, but also from all local earthquakes in eastern side of the linear array (Fig. 6). More specifically, all of the incidence angles estimated at Station W07 were significantly larger than those at Stations W05 and W10.

The consistent phenomenon of larger incidence angles being recorded at stations within and nearby the Chaochou fault might well be attributed to some significant lateral structures beneath the fault zone. One of the most plausible explanations for observing the change of incidence angles across the Chaochou fault is the existence of a LVZ beneath the fault zone. Based on Snell's law, the incidence angle of seismic waves would increase as seismic waves propagate from the high-velocity crust into the low-velocity fault zone across a nearly vertical boundary.

In order to produce a quantitative estimate of the significance of incidence angles due to the presence of lowvelocity zone, two simplified crust structures (with and without a low-velocity zone) across the Chaochou fault were assumed. This allowed us to compare the ray-path characteristics generated by two local earthquakes and recorded at the linear seismic array (Figs. 7 and 8). The crustal model we used was modified according to the one-dimensional velocity structure (Chen 1995). The velocities beneath the Central Range are generally higher than those beneath the Pingtung Plain. A powerful method (Zelt and Smith 1992) that has successfully studied crustal structures in Taiwan (Lin et al. 1999, Lin 2005) was employed to compute two-dimensional ray-paths across the fault zone. At first, the synthetic ray-paths propagated throughout the crustal structure without a significant LVZ showed that incidence angles recorded at all seismic stations of the linear array were similar (Fig. 7).

In contrast, the incidence angles showed significant changes across the fault zone where the LVZ was assumed to be present (Fig. 8). The width as well as the depth of the LVZ was strongly associated with the spatial coverage 
(a)

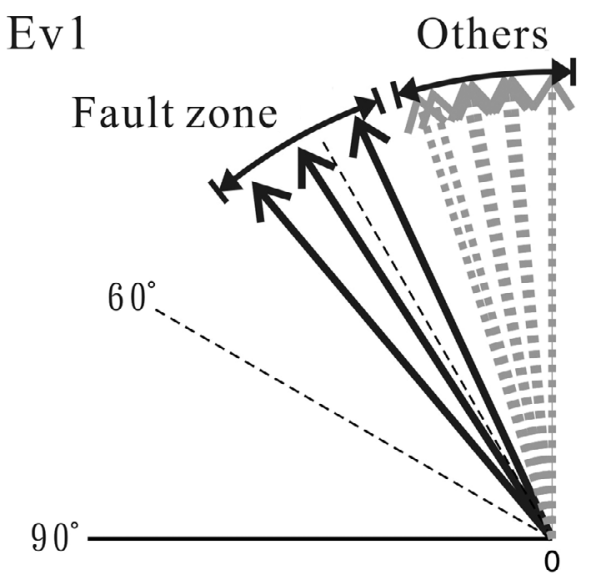

(b)

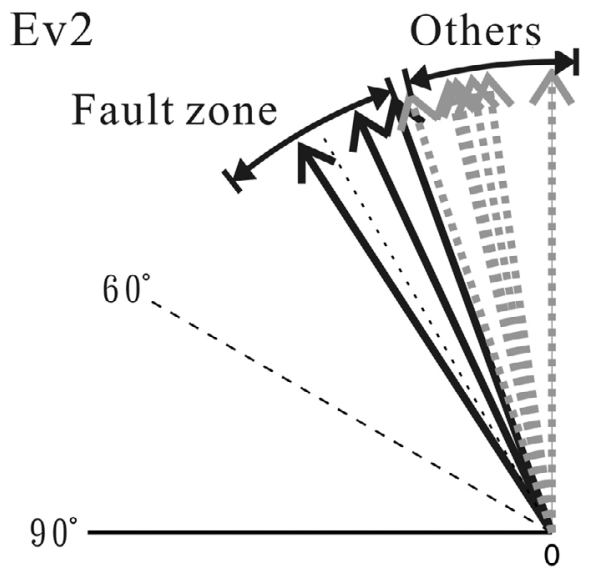

Fig. 5. Comparisons of the incidence angles of the first-motion polarization recorded at the seismic stations in Fig. 1 and generated by (a) Ev1 and (b) Ev2. Solid and dotted arrows show the incidence angles in the fault zone and away from the fault, respectively.

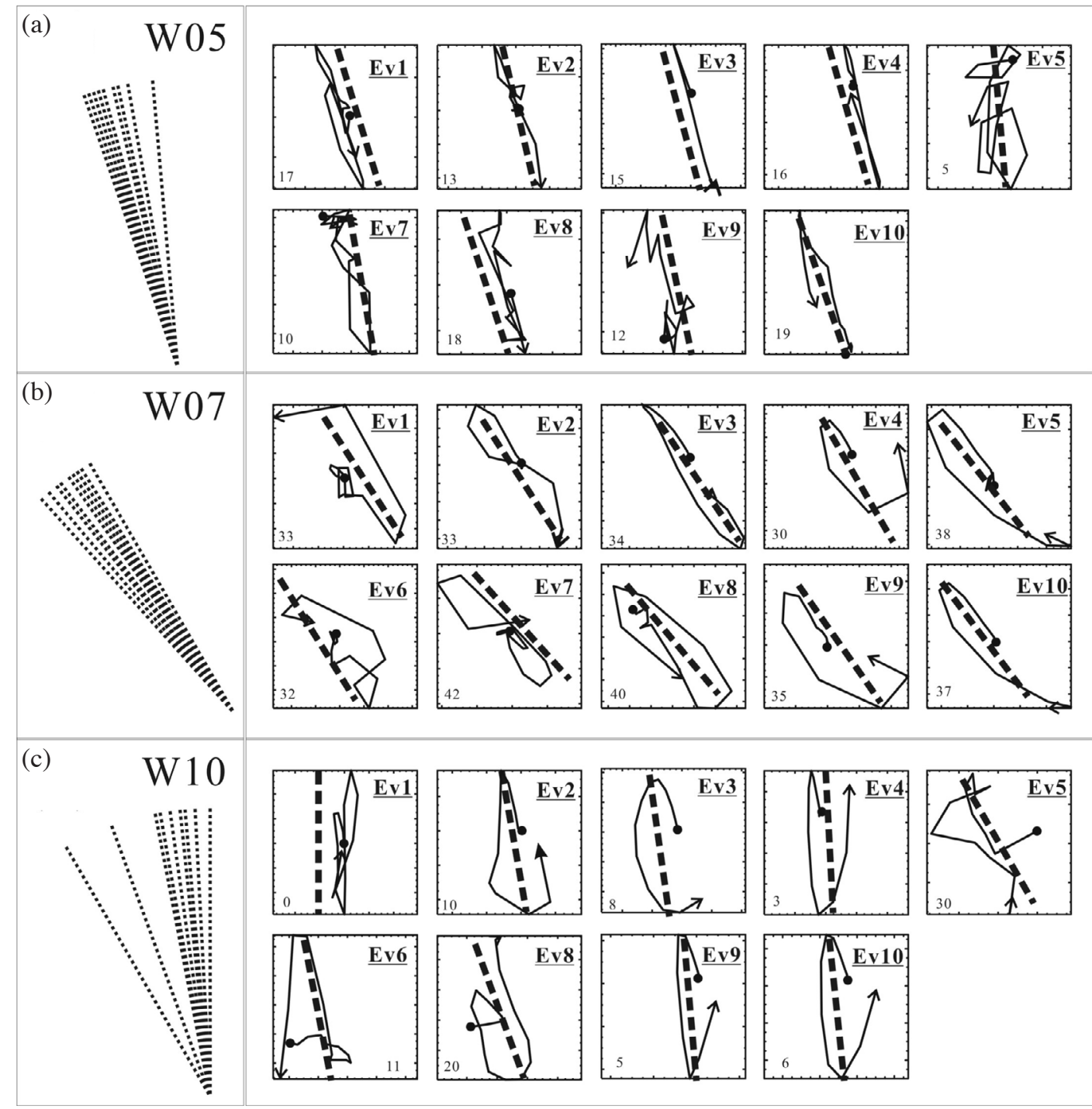

Fig. 6. The estimated incidence angles (the dashed lines in the left panel) and polarizations (thin lines at the right panel) of the first P-waves recorded at Stations (a) W05, (b) W07 and (c) W10. All incidence angles recorded the station (W07) within the fault zone are significantly smaller than those at stations (W05 and W10) away from the fault. 

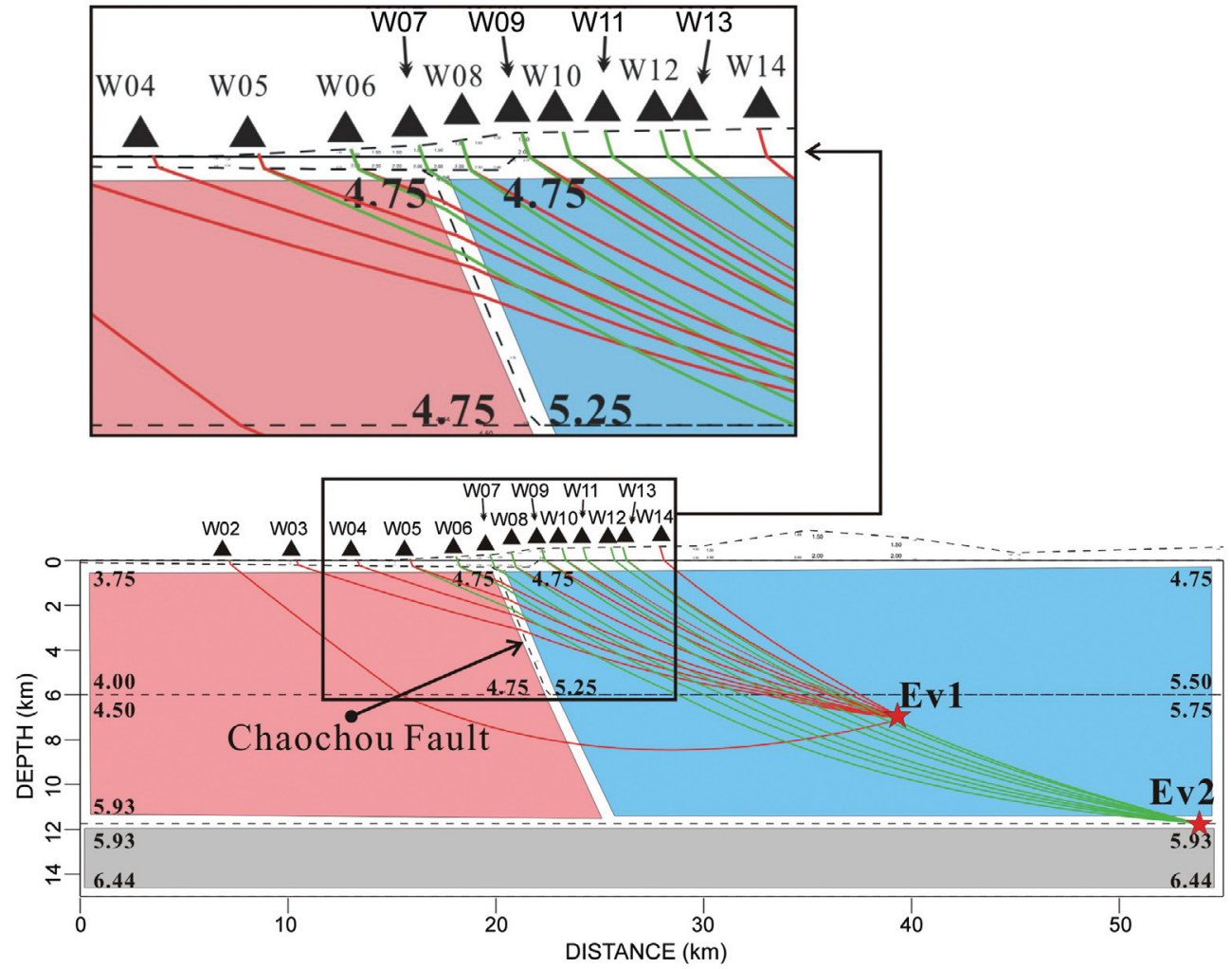

Fig. 7. Ray-paths released from two earthquakes $(\star)$ and arrived at seismic stations $(\boldsymbol{\Delta})$ within the crustal model without a significant low-velocity zone across the Chaochou fault. In the upper crust ( $0-12 \mathrm{~km}$ in depth), the velocities marked in blue at the east of the fault are higher than those marked in pink at the west of the fault.
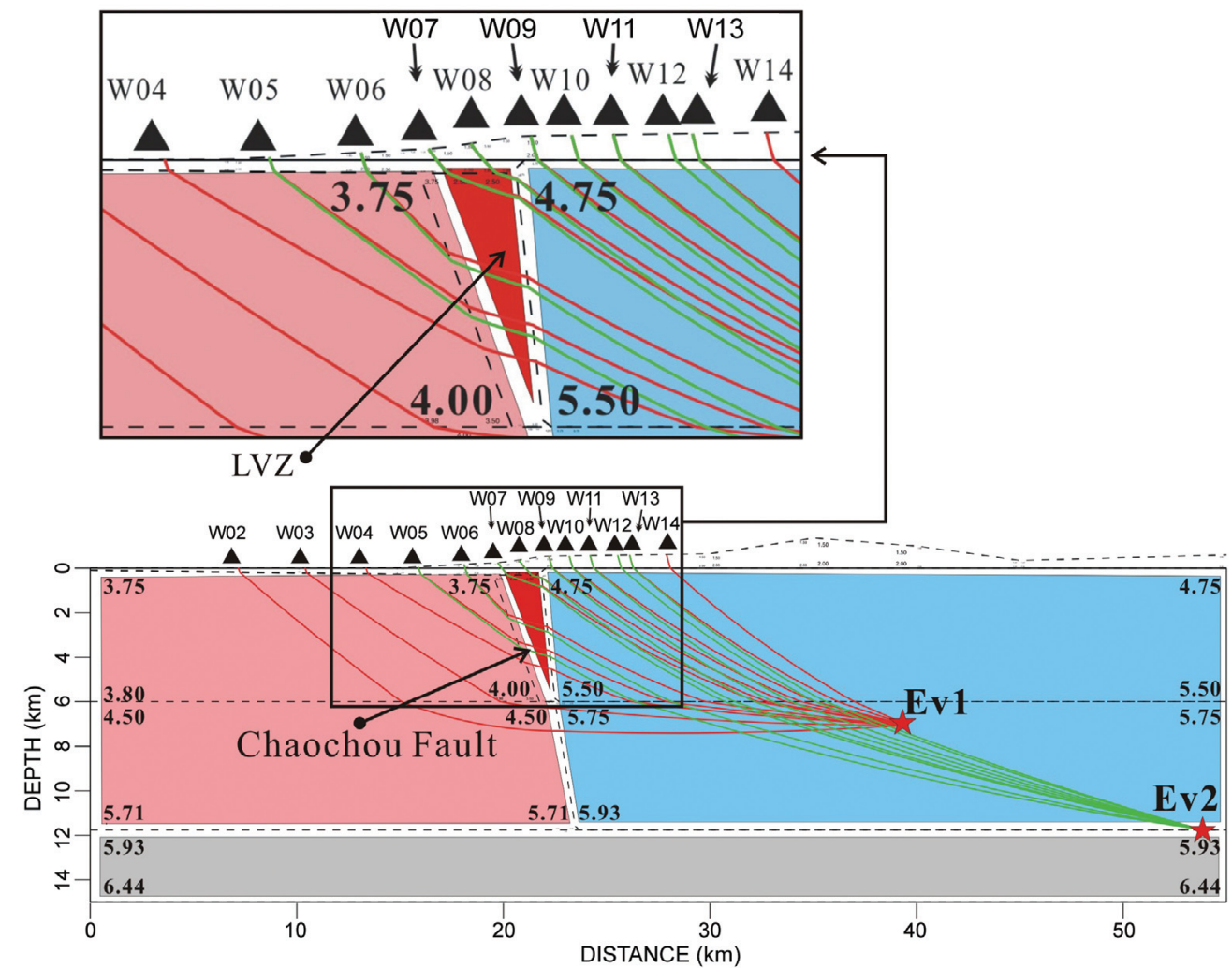

Fig. 8. Ray-paths released from two earthquakes $(\star)$ and arrived at seismic stations $(\mathbf{\Lambda})$ in the crustal model with a significant low-velocity zone marked in red across the Chaochou fault. 
of the anomalous incidence angles recorded at seismic stations (W06 - W08). After some modifications on the crustal model, comparable results between the observed and synthetic incidence angles still required a crustal structure with a LVZ along the Chaochou fault (Fig. 9). Although we do not yet have enough information to configure the exact geometry of the LVZ, using a narrow LVZ provides a plausible explanation for our observations of the incidence angle change across the fault. The width of the LVZ was about $3 \mathrm{~km}$ on the surface, and decreased to a depth of at least $5 \mathrm{~km}$ (Fig. 8). The surface trace of the Chaochou fault is reasonably consistent with the western boundary of the LVZ.

\section{DISCUSSION}

The LVZ beneath the Chaochou fault from the surface down to $\sim 5 \mathrm{~km}$ suggests that several flower structures (Davis and Reynolds 1996; Unsworth et al. 1997; Ben-Zion et al. 2003) might exist near the main fault trace close to the surface. One of the most probable explanations for the LVZ is the existence of a fracture zone near the fault. The $\mathrm{LVZ}$, as wide as $3 \mathrm{~km}$ on the surface, is unlikely to originate from a single fault. Instead, several splay faults might reasonably be expected to produce a fracture zone with low-velocity characteristics in the upper crust (Fig. 10). The major fault slip is shown on the surface trace, and other faults are splayed across the hanging wall of the western Central Range to produce a narrow LVZ from the surface down to a depth of $5 \mathrm{~km}$.
The observation of a low-velocity zone beneath the Chaochou fault further suggests that the faulting processes might have repeatedly occurred along the surface trace as well as the other splay faults on the hanging wall during its geological history. Since the Chaochou fault is the boundary fault between the Coastal Plain and Central Range, some recurring faulting processes might have repeatedly taken place along this geological boundary beginning several million years ago (Chai 1972; Suppe 1984; Angelier et al. 1986; Yen and Tien 1986; Ho 1988; Teng 1990, 1996). Given the strong plate convergence, some faulting processes took

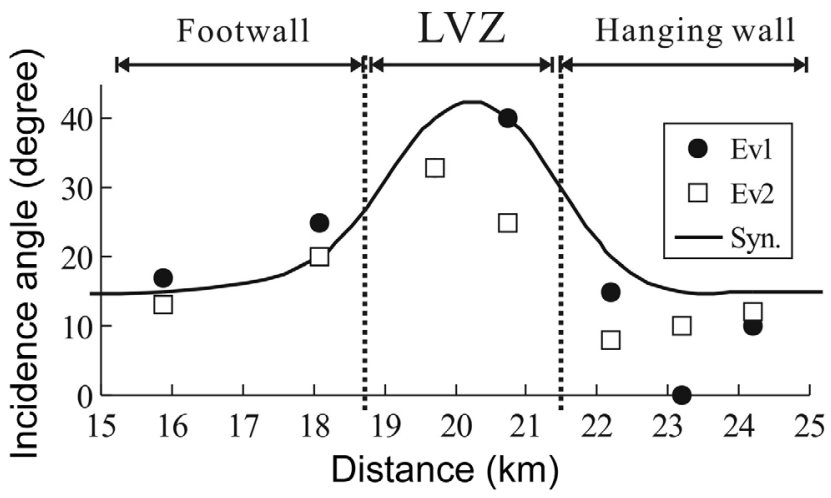

Fig. 9. Comparison of observed and synthetic incidence angles. The solid circles and open squares indicate the observed incidence angles at different distances ( $\mathrm{Y}$ axis is defined as Figs. 7 and 8 ) generated by the sources of Ev1 and Ev2, respectively. The line shows the variation of synthetic incidence angles, which were calculated by the final model.

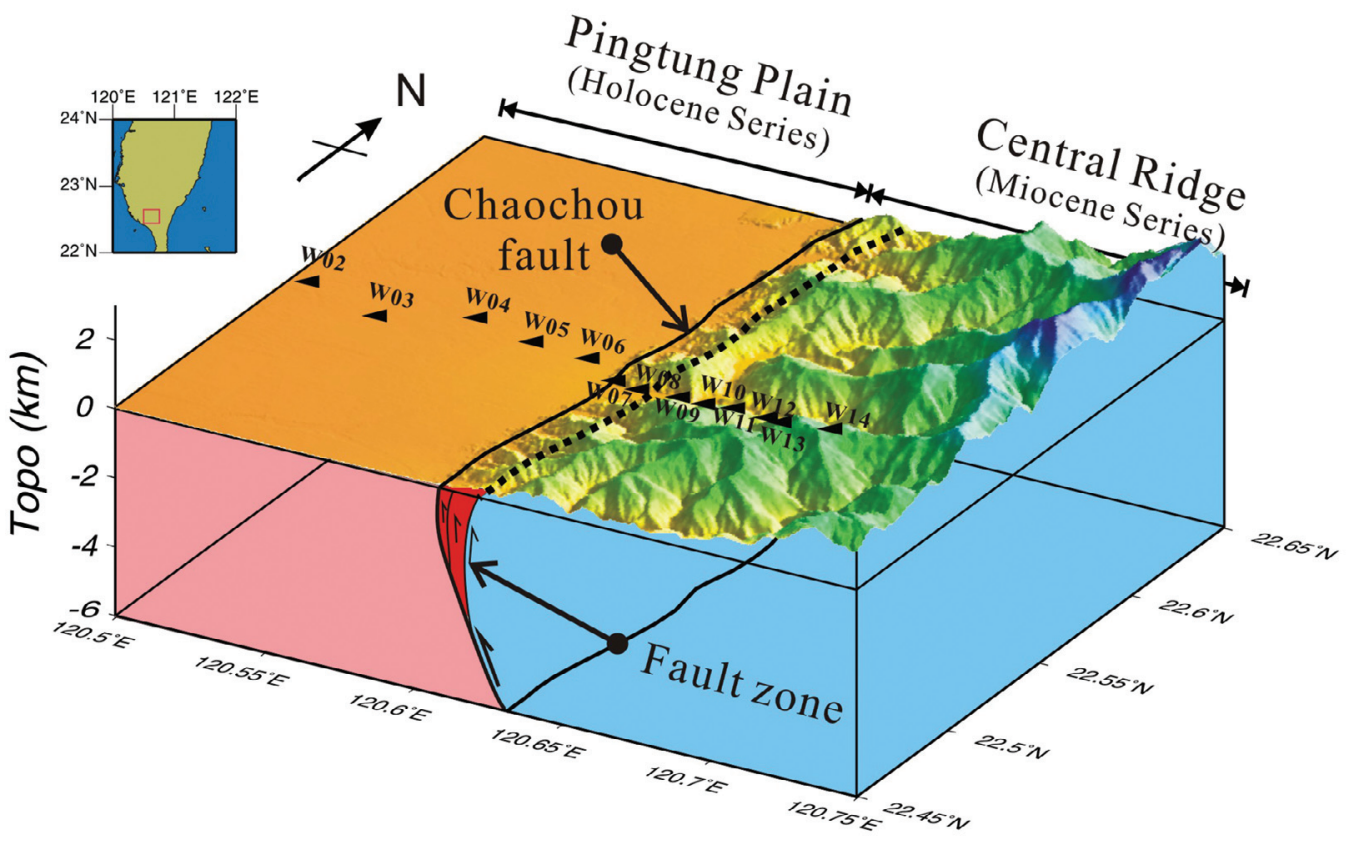

Fig. 10. Schematic model for showing the subsurface structures in and around the Chaochou fault. The Pingtung Plain is separated from the Western Central Range by the Chaochou fault zone with several splay faults on the hanging wall. 
place along the major fault but others might have occurred along other splay faults. Repeated faulting within this narrow fault zone would have generated many fractures and ultimately created a low-velocity zone. Thus, we infer that the Chaochou fault is not a single fault near the surface, but is similar to major boundary faults that consist of several splay faults near the surface, such as the San Andreas Fault, which has been much more thoroughly studied than the Chaochou fault (Unsworth et al. 1997).

\section{CONCLUSION}

To reveal the subsurface structure along the Chaochou fault, seismic data recorded at the linear seismic array have been examined in this study. The incidence angles generated by 10 local earthquakes and recorded at seismic stations near the fault zones were larger than those at other stations away from the fault. This observation directly indicates that there is strong lateral variation of velocity structures across the fault. Further calculation of the ray-paths from the earthquakes to the seismic stations shows that there is a low-velocity zone beneath the Chaochou fault. Although there is not enough evidence to obtain the exact geometry of the low velocity zone, a simplified model approximately $3 \mathrm{~km}$ wide on the surface and $5 \mathrm{~km}$ deep provides a plausible explanation for the changes in incidence angle measurements cross the Chaochou fault. This low-velocity zone might be associated with several splay faults on the uppermost crust of the hanging wall in the Western Central Range. Also, the splay faults within the low-velocity zone suggest that the slips have occurred repeatedly along the Chaochou fault zone during its geological history.

Acknowledgement We would like to thank the Central Weather Bureau for providing its valuable earthquake cata$\log$ for the study area. We also extend our gratitude to the National Science Council, Taipei, Taiwan, for financial support.

\section{REFERENCES}

Angelier, J., E. Barrier, and H. T. Chu, 1986: Plate collision and paleostress trajectories in a fold-thrust belt: The Foothills of Taiwan. Tectonophysics, 125, 161-178.

Ben-Zion, Y., Z. Peng, D. Okaya, L. Seeber, J. G. Armbruster, N. Ozer, A. J. Michael, S. Baris, and M. Aktar, 2003: A shallow fault-zone structure illuminated by trapped waves in the Karadere-Duzce branch of the north Anatolian fault, western Turkey. Geophys. J. Int., 152, 699-717.

Boness, N. L. and M. D. Zoback, 2004: Stress-induced seismic velocity anisotropy and physical properties in the SAFOD Pilot Hole in Parkfield, CA. Geophys. Res. Lett., 31, L15S17, doi: 10.1029/2003GL019020.
[Link]

Bonilla, M. G., 1975: A review of recently active faults in Taiwan. US Geological Survey Open-File Report, 7541, 58 pp.

Bonilla, M. G., 1977: Summary of Quaternary faulting and elevation changes in Taiwan. Mem. Geol. Soc. China, 2, 43-45.

Bonilla, M. G., 1999: A note on historical and Quaternary faults in western Taiwan. US Geological Survey OpenFile Report, 99-447, 5 pp.

Chai, B. H. T., 1972: Structure and tectonic evolution of Taiwan. Am. J. Sci., 272, 389-422.

Chang, C. P., T. Y. Chang, J. Angelier, H. Kao, J. C. Lee, and S. B., Yu, 2003: Strain and stress field in Taiwan oblique convergent system: Constraints from GPS observation and tectonic data. Earth Planet. Sci. Lett., 214, 115-127, doi: 10.1016/S0012-821X(03)00360-1. [Link]

Chen, Y. L., 1995: Three dimensional velocity structure and kinematics analysis in Taiwan area. Master Thesis, National Central University, Jhongli, Taiwan, ROC, $172 \mathrm{pp}$.

Chéry, J., M. D. Zoback, and S. Hickman, 2004: A mechanical model of the San Andreas fault and SAFOD Pilot Hole stress measurements. Geophys. Res. Lett., 31, L15S13, doi: 10.1029/2004GL019521. [Link]

Chiang, S. C., 1971: Seismic study of the Chao-Chou structure, Pingtung, Taiwan. Petrol. Geol. Taiwan, 8, 281294.

Ching, K. E., R. J. Rau, J. C. Lee, and J. C. Hu, 2007: Contemporary deformation of tectonic escape in SW Taiwan from GPS observations, 1995-2005. Earth Planet. Sci. Lett., 262, 601-619, doi: 10.1016/j.epsl.20 07.08.017. [Link]

Davis, G. H. and S. J. Reynolds, 1996: Structural Geology of Rocks and Regions (2 ${ }^{\text {nd }}$ Edition), New York, John Wiley and Sons, Inc., 776 pp.

Hassler, L., 2004: Motion and evolution of the Chaochou fault, southern Taiwan. Master Thesis, Texas A\&M University, Texas, USA.

Ho, C. S., 1988: An Introduction to the Geology of Taiwan: Explanatory Text of the Geologic Map of Taiwan. Ministry of Economic Affairs, Taipei, Taiwan, ROC, $192 \mathrm{pp}$.

Howard, A. D., 1962: The Chungchou photogeologic anomalies. Petrol. Geol. Taiwan, 1, 121-125.

Hsieh, S. H., 1970: Geology and gravity anomalies of Pingtung Plain, Taiwan. Proc. Geol. Sco. China, 13, 76-89.

Hsu, T. L. and H. C. Chang, 1979: Quaternary faulting in Taiwan. Mem. Geol. Soc. China, 3, 155-165.

Ito, H. and Y. Kuwahara, 1996: Trapped waves along the Nojima fault from the aftershock of Kobe earthquake, 1995. Proceedings of VIIIth International Symposium on the observation of the Continental Crust Trough 
Drilling, 399-402.

Ito, H., Y. Kuwahara, T. Miyazai, O. Nishizawa, T. Kiguchi, K. Fujimoto, Y. Ohtani, H. Tanaka, T. Higuchi, S. Agar, A. Brie, and H. Yamamoto, 1996: Structure and physical properties of the Nojima fault by the Active fault drilling. Geophys. Explor., 49, 522-535.

Kuwahara, Y., K. Imanishi, and H. Ito, 2001: Seismic trapped wave observation in the fault zone of the Western Tottori earthquake of 2000. Program abstract of Japan Earth and Planetary Science Joint meeting.

Li, Y. G., P. Leary, K. Aki, and P. Malin, 1990: Seismic trapped modes in the Oroville and San Andreas fault zones. Science, 249, 763-766, doi: 10.1126/scie nce.249.4970.763. [Link]

Li, Y. G., K. Aki, D. Adams, A. Hasemi, and W. H. K. Lee, 1994: Seismic guided waves trapped in the fault zone of the Landers, California, earthquake of 1992. J. Geophys. Res., 99, 11705-11722, doi: 10.1029/94JB00464. [Link]

Lin, C. H., 2002: Active continental subduction and exhumation: The Taiwan orogeny. Terr. Nova, 14, 281-287.

Lin, C. H., 2005: Identification of mantle reflections from a dense linear seismic array: Tectonic implications to the Taiwan orogeny. Geophys. Res. Lett., 32, L06315, doi: 10.1029/2004GL021814. [Link]

Lin, C. H., B. S. Huang, and R. J. Rau, 1999: Seismological evidence for a low-velocity layer within the subducted slab of southern Taiwan. Earth Planet. Sci. Lett., 174, 231-240, doi: 10.1016/S0012-821X(99)00255-1. [Link]

Lin, C. W., H. C. Chang, S. T. Lu, T. S. Shih, and W. J. Huang, 2000: An introduction to the active faults of Taiwan. Central Geological Survey Special Publica- tion, 13, $122 \mathrm{pp}$.

Morrow, C., J. Solum, S. Tembe, D. Lockner, and T. F. Wong, 2007: Using drill cutting separates to estimate the strength of narrow shear zones at SAFOD. Geophys. Res. Lett., 34, L11301, doi: 10.1029/2007GL029665. [Link]

Shin, T. C., K. W. Kou, W. H. K. Lee, T. L. Teng, and Y. B. Tsai, 2000: A preliminary report on the 1999 Chi-Chi (Taiwan) earthquake. Seismol. Res. Lett., 71, 23-29.

Suppe, J., 1984: Kinematics of arc-continent collision, flipping of subduction and back-arc spreading near Taiwan. Mem. Geol. Soc. China, 6, 21-33.

Teng, L. S., 1990: Geotectonic evolution of late Cenozoic arc-continent collision in Taiwan. Tectonophysics, 183, 57-76, doi: 10.1016/0040-1951(90)90188-E. [Link]

Teng, L. S., 1996: Extensional collapse of the northern Taiwan mountain belt. Geology, 24, 945-952.

Unsworth, M. J., P. E. Malin, G. D. Egbert, and J. R. Booker, 1997: Internal Structure of the San Andreas fault at Parkfield, California. Geology, 25, 359-362, doi: 10.11 30/0091-7613(1997)025<0359:ISOTSA>2.3.CO;2. [Link]

Wiltschko, D. V., J. H. Hung, P. Hang, and Y. Bock, 2002: Motion along the Eurasian-Philippine Sea plate boundary in the Longitudinal Valley, Taiwan from GPS. Eos, Trans., AGU, 83, Fall Meet. Suppl., Abstract \#T61B1257.

Yen, T. P. and P. L. Tien, 1986: Chaochou fault in Southern Taiwan. Proc. Geol. Soc. China, 29, 9-22.

Zelt, C. A. and R. B. Smith, 1992: Seismic traveltime inversion for 2-D crustal velocity structure. Geophy. J. Int., 108, 16-34, doi: 10.1111/j.1365-246X.1992.tb008 36.x. [Link] 